\title{
Characterization of Coating Formed on Pure Zirconium by MAO in Yttrium Acetate Tetrahydrate Containing Electrolyte
}

\author{
S. Cengiz ${ }^{a}$, M. YAZICI ${ }^{a, b}$, Y. GenCER ${ }^{a, *}$, M. TARAKCI ${ }^{a}$ \\ ${ }^{a}$ Gebze Institute of Technology, Department of Materials Science \\ and Engineering, 41400 Gebze, Kocaeli, Turkey \\ ${ }^{b}$ Ondokuz Mayis University, Department of Materials Science \\ and Engineering, 55139 Kurupelit, Samsun, Turkey
}

\begin{abstract}
In this study, oxide coatings were produced on pure zirconium by micro arc oxidation method in the electrolytes containing sodium silicate and different amounts of yttrium acetate tetrahydrate $(1-4 \mathrm{~g} / \mathrm{l})$ for the same coating duration of $1 \mathrm{~h}$. The surface roughness, microstructure, phase content and chemical composition of the coatings were characterized by using scanning electron microscopy, profilometry and X-Ray diffractometry. It was found that the surfaces of coatings on zirconium consist of monoclinic- $\mathrm{ZrO}_{2}$, tetragonal- $\mathrm{ZrO}_{2}$ phases. The coating thickness decreases with addition of yttrium acetate tetrahydrate while it does not change significantly with the increase of its amount. The clustered equiaxed features were formed on the surfaces of the coatings. As the amount of yttrium acetate tetrahydrate in the electrolyte solution increased, the coating/substrate interface smoothened. Two main regions of the coating, the outer dense region (I) and the porous inner region (II), became significant with addition of YAT into the electrolyte.
\end{abstract}

DOI: $10.12693 /$ APhysPolA.127.1320

PACS: 81.15.-z, 81.05.Bx.

\section{Introduction}

Due to their outstanding mechanical, biocompatibility and neutron absorption properties, zirconium and its alloys are extensively used in medical applications and chemical industry [1-5]. Unfavorable environmental conditions limit the working life and occasion for enhancing area of usage. It is possible to make long living metallic materials by enhancing surface properties without changing bulk properties. Various surface modification techniques are applied to improve the chemical and mechanical properties against corrosion and wear. For the purpose, traditional and novel coating methods can be applied for coating of zirconium and its alloy such as spray coating, electrophoretic deposition, dip coating, sol-gel techniques, ion beam deposition, physical or chemical deposition processes [6-10]. However, these techniques have some disadvantages such as high cost, low coating rate, difficulty for coating of complex shaped parts. Furthermore, heat treatments needed after/during coating may evoke cracking, spallation of the film or change in bulk properties of the substrate [6-10]. MAO is also called plasma electrolytic or anodic spark deposition is a plasma-chemical and electrochemical based process [11-15]. Although MAO process is based on conventional anodic oxidation of valve metals in aqueous solution, it is operated with considerably at higher breakdown voltage which results in very short lived spark discharge. Zirconium is one of those metals whose surface

*corresponding author; e-mail: gencer@gyte.edu.tr can be modified by MAO coating method which forms different polymorphs of $\mathrm{ZrO}_{2}$. In ambient atmospheric pressure, $\mathrm{ZrO}_{2}$ consists of the three main polymorphs phase; monoclinic $\left(\mathrm{m}-\mathrm{ZrO}_{2}\right)$, tetragonal $\left(\mathrm{t}-\mathrm{ZrO}_{2}\right)$ and $\mathrm{cu}-$ bic $\left(\mathrm{c}-\mathrm{ZrO}_{2}\right)$. At room temperature monoclinic phase is stable and the transformation of monoclinic to tetragonal takes place at $1170{ }^{\circ} \mathrm{C}$ and from tetragonal to cubic takes place at $2370{ }^{\circ} \mathrm{C}[16]$. The phases of $\mathrm{t}-\mathrm{ZrO}_{2}$ and c- $\mathrm{ZrO}_{2}$ can be stabilized at room temperature by the addition of some stabilizers such as $\mathrm{MgO}, \mathrm{Y}_{2} \mathrm{O}_{3}, \mathrm{CaO}$ and $\mathrm{SiO}_{2}$ [17]. In our previous study, MAO of pure zirconium was carried out in electrolyte with different amounts of sodium silicate for two hours. It was found that the coatings consist of $\mathrm{m}-\mathrm{ZrO}_{2}$ and $\mathrm{t}-\mathrm{ZrO}_{2}$ phases and increasing amount of sodium silicate concentration in the electrolyte resulted in increase of the amount of $\mathrm{t}-\mathrm{ZrO}_{2}$ phase and the coating thickness [11]. In another study it was found that the main phases in the coatings are $\mathrm{t}-\mathrm{ZrO}_{2}$ and $\gamma-\mathrm{Al}_{2} \mathrm{O}_{3}$ with higher rate of coating formation in an electrolyte containing different concentration of aluminate $(8-32 \mathrm{~g} / 1)$ for MAO of $\mathrm{Zr}-2$ [18]. On the other hand it was reported that MAO coatings formed on $\mathrm{Zr}-4$ alloy in the electrolyte containing pyrophosphate consisted only $\mathrm{m}-\mathrm{ZrO}_{2}$ as main phase [2].

In the present work, MAO coatings formed on pure zirconium were studied using different electrolytes of sodium silicate and addition of different amount of yttrium acetate tetrahydrate (YAT) into sodium silicate. The microstructure and phase compositions of the coatings formed in these electrolytes were characterized by scanning electron microscopy (SEM), profilometry and $\mathrm{X}$-Ray diffractometry (XRD). 


\section{Experimental}

The pure zirconium sheet was cut to have rectangular shaped specimens with working area $25 \mathrm{~mm} \times 50 \mathrm{~mm} \times 1 \mathrm{~mm}$. The samples were ground using 240-1200 grit $\mathrm{SiC}$ paper and the polished using $3-1 \mu \mathrm{m}$ alumina colloidal solution. The surface roughness of the bare $\mathrm{Zr}$ substrates was measured by scanning an area of $5 \mathrm{~mm} \times 5 \mathrm{~mm}$ with 20 scan by employing Dektak 8 Profilometer. The electrolytes with four different compositions were prepared by using a certain amount of sodium silicate and YAT by dissolving in distilled water as given in the Table. These electrolyte compositions were here in after referred to as A1, A2, A3 and A4. The MAO coating was carried out by employing a

The chemical compositions of the electrolytes. TABLE

\begin{tabular}{c|c|c|c|c}
\hline \hline Electrolytic composition & A1 & A2 & A3 & A4 \\
\hline Sodium silicate $[\mathrm{g} / \mathrm{l}]$ & 12 & 12 & 12 & 12 \\
Yttrium acetate tetrahydrate $[\mathrm{g} / \mathrm{l}]$ & 0 & 1 & 2 & 4
\end{tabular}

home-made asymmetric AC power supply. The MAO coating duration for each sample was 60 minutes. Upon coating $\mathrm{Zr}$ samples, they were successively washed in distilled water, washed in ethanol and dried under warm air flow. The surface roughness of the MAO coated samples was evaluated by using the same Profilometer with the same parameters used for bare Zr. Rigaku D-MAX 2200 X-ray diffractometer (40 kW, $40 \mathrm{~mA})$, with a CuK_alpha radiation over a $2 \theta=20^{\circ}$ to $100^{\circ}$, was employed for the characterization of MAO coating formed on $\mathrm{Zr}$ substrates. The surfaces of MAO coated samples were examined using Phillips XL30 electron scanning microscope (SEM), equipped with energydispersive $\mathrm{X}$ - ray spectroscopy (EDS). Then the samples were cut, mounted into epoxy resin, ground and polished to expose the cross-sectional view of the coatings. The microstructural examination and determination of the chemical composition of the MAO coated samples were carried out by cross-sectional SEM with regional EDS analysis.

\section{Results}

\section{1. $X R D$}

XRD patterns obtained from the surface of the MAO coatings formed in A1, A2, A3 and A4 (Table) electrolytes are given in Fig. 1. The patterns revealed that the coating was composed of $\mathrm{m}-\mathrm{ZrO}_{2}$ and $\mathrm{t}-\mathrm{ZrO}_{2}$ phases for all coatings. There is no considerable difference among the XRD spectra of the coatings.

\subsection{Coating thickness and surface roughness}

Figure 2 shows the measurements of the average coating thickness and surface roughness $(\mathrm{Ra})$ of the coatings formed on $\mathrm{Zr}$ in different electrolytes of A1, A2, A3 and A4. Figure 2 shows that the maximum coating thickness was measured as $70 \mu \mathrm{m}$ with the average thickness value

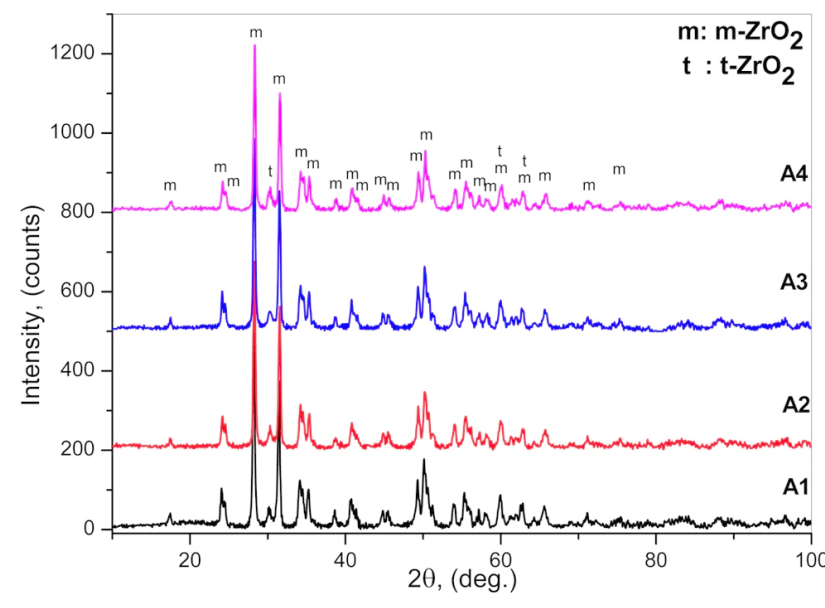

Fig. 1. The surface XRD patterns of MAO coating formed on zirconium substrate in A1, A2, A3 and A4 electrolytes.

of $62 \mu \mathrm{m}$ for A1 electrolyte (without YAT). The coating thickness slightly decreases with the presence of YAT (approximately $50 \mu \mathrm{m}$ ) in electrolyte. But the increase of YAT amount (from $1 \mathrm{~g} / 1$ to $4 \mathrm{~g} / \mathrm{l}$ ) in MAO coating electrolyte has no considerable effect on the oxide coating thickness formed on pure Zr. Figure 2 also shows that the average surface roughness values changed from $6.85 \mu \mathrm{m}$ to $8.23 \mu \mathrm{m}$ depending on the electrolytic solution while the surface roughness of the bare zirconium substrates just before coating was approximately $0.16 \mu \mathrm{m}$. The figure shows that there is no clear effect of YAT on the surface roughness values of the MAO coatings formed on $\mathrm{Zr}$.

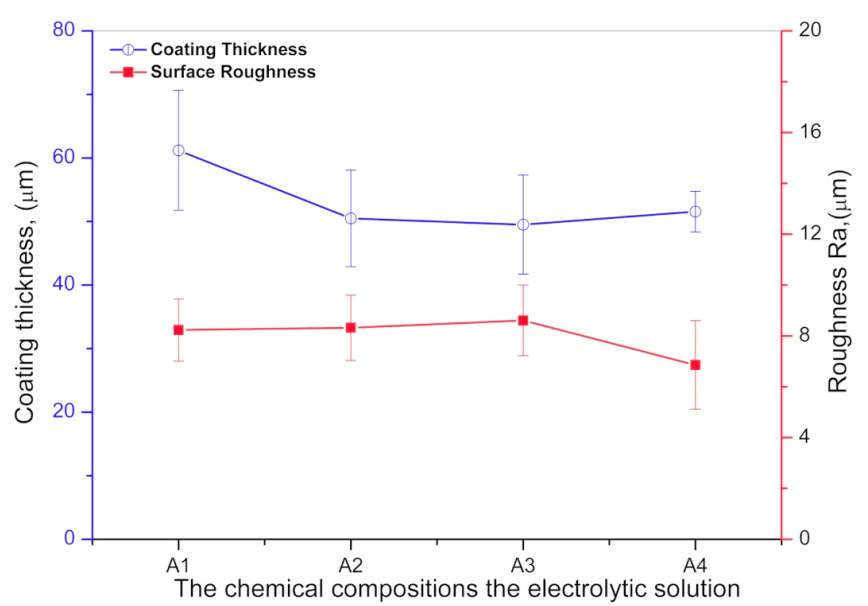

Fig. 2. The change in coating thickness and surface roughness ( $\mathrm{Ra}$ ) with MAO coating of $\mathrm{Zr}$ in A1, A2, A3 and A4 electrolytes.

\subsection{Microstructure and chemical analysis}

Figure 3a, 3b, 3c and 3d illustrate the surface morphology of the coatings formed on $\mathrm{Zr}$ in electrolytes of A1, A2, A3 and A4. The surface of the coatings contains various shapes such as porous and the small spherical features with partly sponge-like irregular appearance. On 
the surface of the coatings there are also pores which surrounded by materials residue. Some of these residues are in equiaxed form which was seen as typical feature on MAO coated $\mathrm{Zr}$ and its alloys [1-4, 11]. Figure 3a, $3 \mathrm{~b}, 3 \mathrm{c}$ and $3 \mathrm{~d}$ reveal that the presence of YAT in the electrolyte affects the amount of pore concentration and size. Amount and average size of pores increased with YAT addition $(1 \mathrm{~g} / \mathrm{l})$ to the electrolyte but its further addition has not considerable effect on the surface morphology of the coatings. Figure 4 shows the cross sectional SEM image of the coating formed on $\mathrm{Zr}$ in $\mathrm{A} 1$, A2, A3 and A4 electrolytes. The oxide coating, which adhered to pure Zr substrate very well, has two main regions; the outer region (I) having dense appearance with some cracks and small pores, the inner region (II) having porous appearance with well distributed relatively larger pores. The distinction of the region I and II became significant with addition of YAT into the electrolyte. Although the coating/substrate interface is nonuniform for the sample coated in A1 electrolyte, the coating/substrate interface smoothens with addition and increasing amount of YAT in the electrolyte. Furthermore, the addition of YAT into the electrolyte and increase in its amount result in the uniform thicknesses of the region I and II of coating and consequently total thickness of the oxide coating. It is also seen from Fig. 4 that there is a clear crack parallel to the surface of the coating between the region I and II. Moreover, the largest pores are seen on these cross sectional SEM images of the coating in the border of the outer and inner region. Figure 5 illustrates typical surface SEM image (Fig. 5a) of the coating formed in electrolyte A4 with regional SEM-EDS spectra (Fig. 5b-c) acquired from three regions (A) and (B) marked on Fig. 5a for main constituents of $\mathrm{O}, \mathrm{Si}, \mathrm{Y}, \mathrm{Zr}$, $\mathrm{Na}$ in the coatings. The SEM-EDS results clarify that the relative amounts of $\mathrm{Si}$ and $\mathrm{Na}$ (Fig. $5 \mathrm{c}$ ) in the spongy region marked as "B" in Fig. 5a is higher than that of (Fig. 5b) in the region having equiaxed feature marked "A" in Fig. 5a. A typical cross sectional SEM image is given in Fig. 6a and SEM-EDS spectra obtained from its marked areas of "X", "Y" and "Z" are given in Figures $6 \mathrm{~b}, 6 \mathrm{c}$ and $6 \mathrm{~d}$ respectively. These spectra show that the coatings contain $\mathrm{O}, \mathrm{Na}, \mathrm{Si}, \mathrm{Y}$ and $\mathrm{Zr}$ elements with some amount of $\mathrm{C}$. The relative amount of $\mathrm{Zr}$ element almost is the same (Fig. 6b) both in glassy outer region (" $\mathrm{X}$ " in Fig. 6a) and relatively in porous inner regions (Fig. 6d) ("Z" in Fig. 6a) while the relative amount of Si decreased in the inner region of the coatings. However, the relative amount of $\mathrm{O}$ is approximately constant through the coating.

\section{Discussion}

$\mathrm{ZrO}_{2}$ can be present in three crystal structure phases in different temperature intervals (monoclinic, tetragonal, cubic) while only $\mathrm{m}-\mathrm{ZrO}_{2}$ is stable at room temperature under equilibrium conditions [16]. The transformation of monoclinic to tetragonal phase occurs at $1170{ }^{\circ} \mathrm{C}$ and from tetragonal to cubic transformation occurs at $2370{ }^{\circ} \mathrm{C}$. When the temperature of the coating decreases
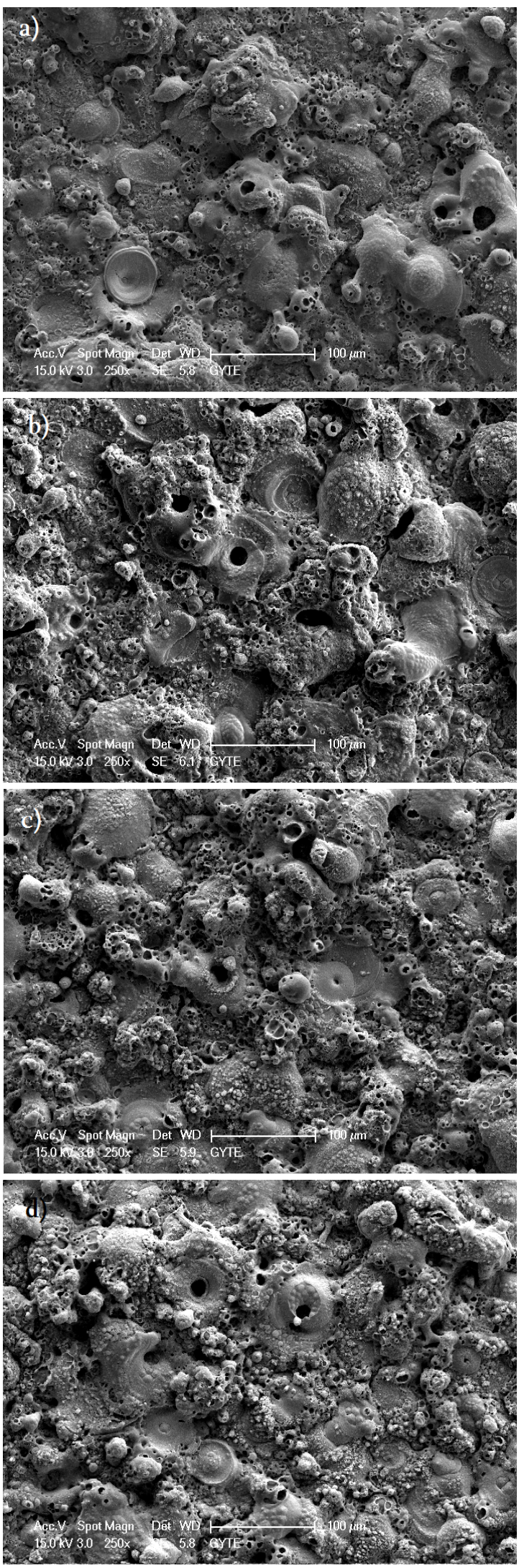

Fig. 3. The surface SEM micrographs of MAO coated $\mathrm{Zr}$ with different electrolytes; (a) A1, (b) A2, (c) A3 and (d) A4 (Table). 

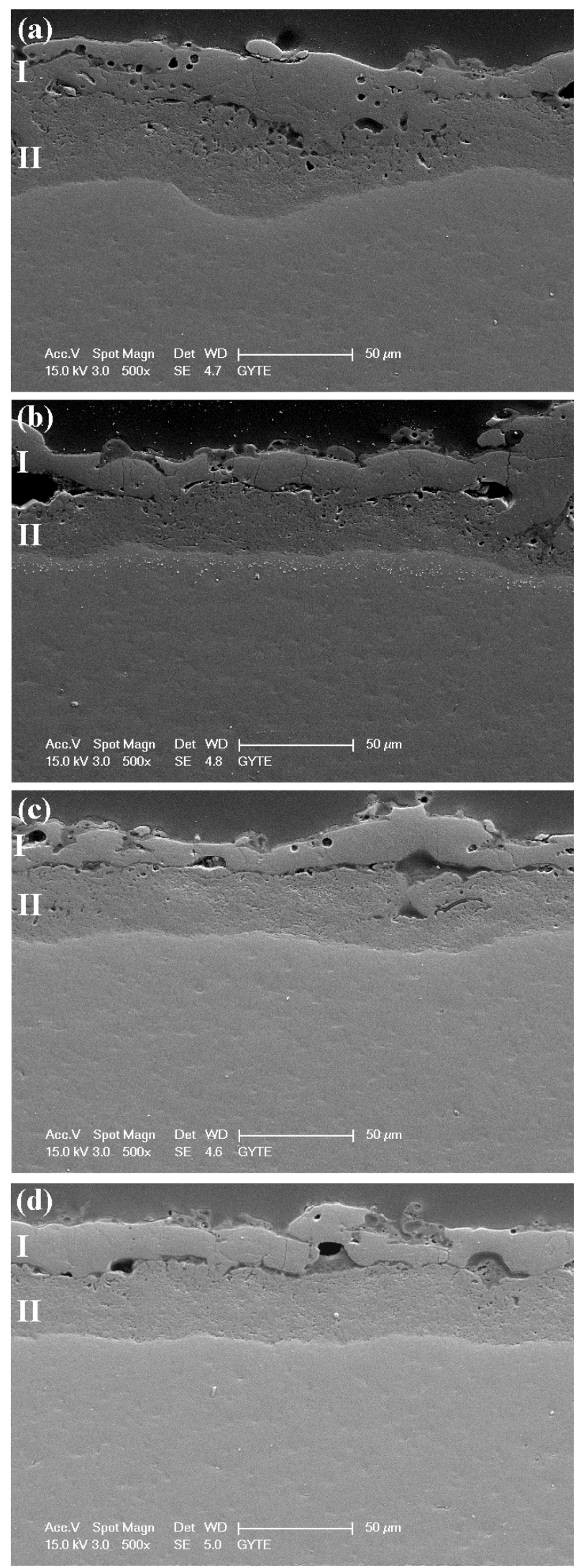

Fig. 4. The cross section SEM micrographs of MAO coated $\mathrm{Zr}$ with different electrolyte; (a) A1, (b) A2, (c) A3 and (d) A4 (Table).
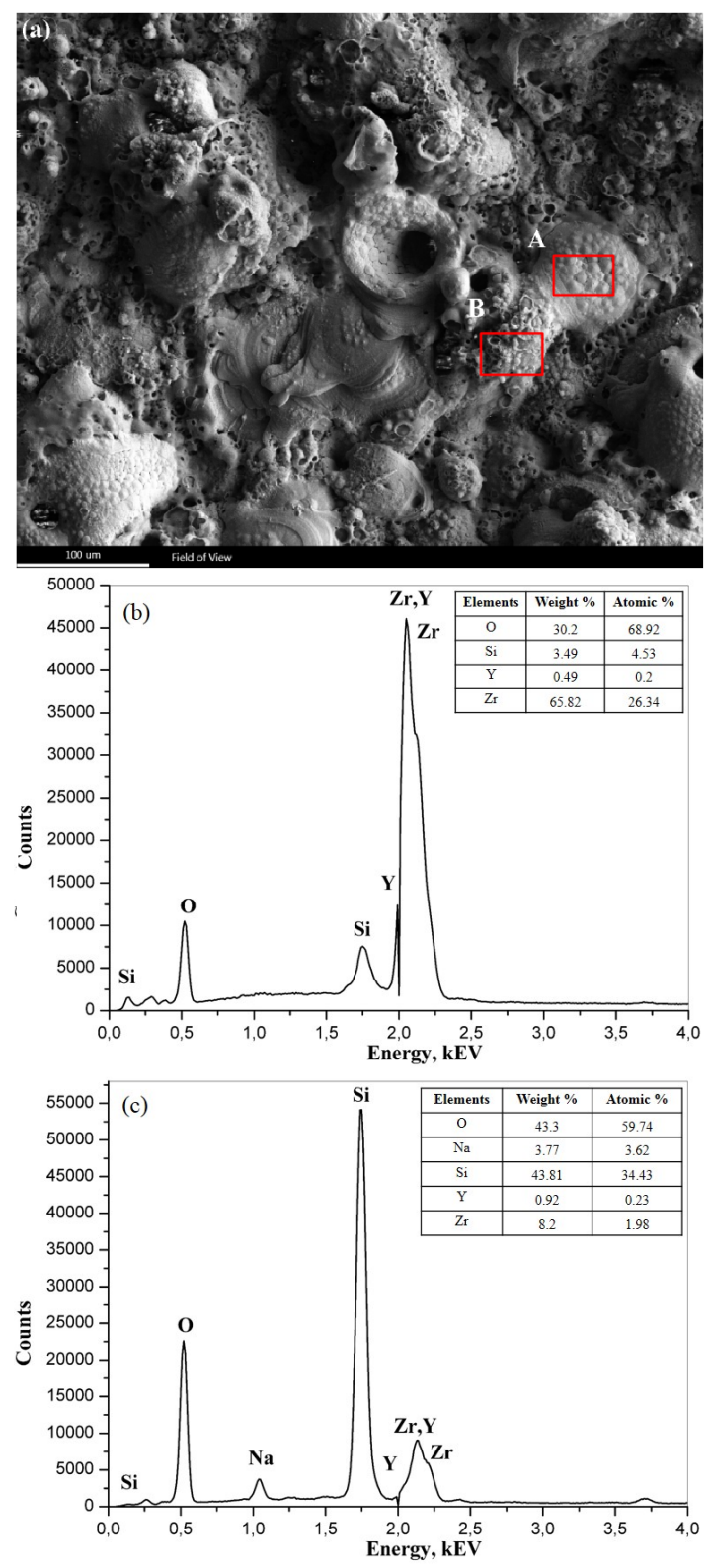

Fig. 5. Surface SEM micrograph of MAO coating of $\mathrm{Zr}$ in electrolyte A4 and the SEM-EDS spectra from its certain areas; (a) SEM image, (b) area "A" and (c) area "B".

below $1200{ }^{\circ} \mathrm{C}$, $\mathrm{t}-\mathrm{ZrO}_{2}$ transforms into $\mathrm{m}-\mathrm{ZrO}_{2}$ partly because of rapid cooling with the contact of cold electrolyte. The cracks observed in the cross section and surface of the coatings are possibly caused by these phase transformations and thermal stresses. Though $\mathrm{t}-\mathrm{ZrO}_{2}$ is a high temperature phase, it can be stabilized at room temperature by several oxides such as $\mathrm{MgO}, \mathrm{Y}_{2} \mathrm{O}_{3}$ and $\mathrm{CaO}$ [17]. In addition to these stabilizing agents, during the MAO processes, when the temperature of molten metal and metal-oxide suddenly decrease, $\mathrm{ZrO}_{2}$ phases can be stabilized in various crystal structures because of non-equilibrium transformation because of rapid cooling effect of the cold electrolyte. As seen from the XRD pat- 

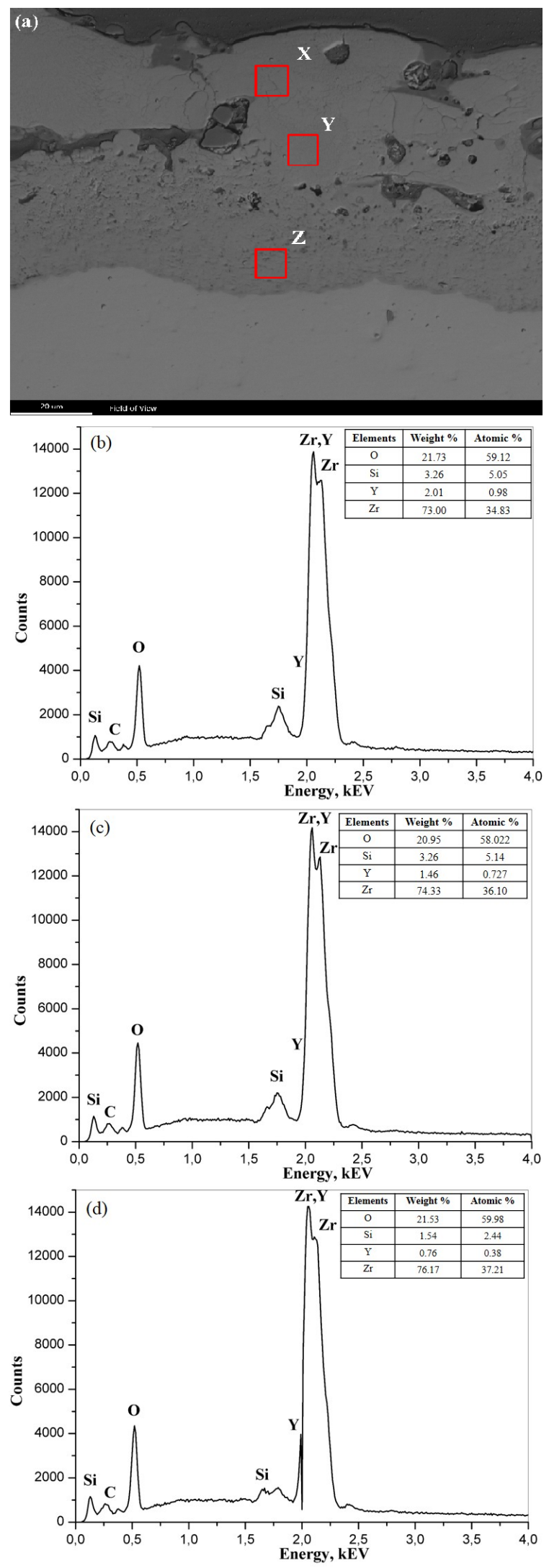

Fig. 6. Cross-sectional SEM micrographs of MAO coating of $\mathrm{Zr}$ in electrolyte A4 and the SEM-EDS spectra from its certain areas; (a) SEM image, (b) area " $X$ ", (c) area "Y" and (d) area "Z". terns all of the coatings are composed of $\mathrm{m}-\mathrm{ZrO}_{2}$ and $\mathrm{t}-\mathrm{ZrO}_{2}$ phases. The presence of $\mathrm{t}-\mathrm{ZrO}_{2}$ can be attributed to the partial stabilization effect of $\mathrm{t}-\mathrm{ZrO}_{2}$ because of non-equilibrium transformation.

Some pores, micro and macro cracks can be seen on the coating surfaces. Formation of these pores could be the result of the gas bubbles and molten metal-oxide thrown out of spark discharged channels. In addition to the cracks are caused by thermal stress and phase transformation in the fast solidification of molten metal-oxide when the coating surface contacts with the cold electrolyte. The surface of coating formed by MAO in the different electrolytes created pancake-like features (Fig. 3a, $c, d)$. The relatively big holes in the center of the pancake features indicate that intense spark discharges are generated during the process. Also, these holes are thought to be the entrance of the discharge channels, which extend from surface to coating-substrate interface.

Figure 3 and Fig. 5a show a special structure on the coating surface, which consist of cluster of equiaxed dendrites. These structures are similar to the features reported in previous studies [1-4, 11]. Electron avalanches formed during $\mathrm{MAO}$ process results in generation of intense spark discharges. It was explained that owing to the local high temperature and strong electrical field, molten metal and metal-oxide are ejected from the discharge channels to the coating surface. Thus, cluster of equiaxed dendrites are formed as a result of rapid solidification of ejected material under certain special conditions [1].

The coatings formed on pure $\mathrm{Zr}$ consisted of the two distinct layers. The inner layer is mainly composed of $\mathrm{Zr}$ and $\mathrm{O}$ which implies that materials transferred from the deepest region of the coating whereas the outer layer is rich in silicon. This can be attributed to the substrate oxidation nature of the MAO coating as the coatings grow inward and outward during the process. The presence of the glassy phase is due to accumulation and reaction of silicate ions with molten metal and metal-oxide which resulted in compact, smooth and glassy outer surface while the relatively porous inner layer is because of the trap of evaporated materials. Furthermore, the diffusion of oxygen from the electrolyte endorsed the coating thickness to increase. The coating/substrate interface became smoother and surface roughness tended to decrease with the addition and increase amount of YAT in electrolyte. This phenomenon can be attributed to increasing homogeneity of both distribution of discharge channels and intensity of the spark energy with increasing YAT content.

\section{Conclusions}

The oxide based coatings which adhered to pure $\mathrm{Zr}$ substrate very well were produced on pure zirconium by MAO method in the electrolytes containing sodium silicate and different amounts of YAT for $1 \mathrm{~h}$ and the following conclusions obtained;

The oxide coating has two main regions; the outer dense region (I) with some cracks and small pores and 
the porous inner region (II). The distinction of the region I and II became significant with addition of YAT into the electrolyte.

The coatings are mainly composed of $\mathrm{t}-\mathrm{ZrO}_{2}$ and $\mathrm{m}-\mathrm{ZrO}_{2}$ phases. The features of equiaxed dendritic cluster were observed around the plasma channels on the surface coating of $\mathrm{Zr}$.

The equiaxed dendritic clusters consist of $\mathrm{Zr}, \mathrm{O}$ rich and which of surroundings have Si and Y rich.

The coating/substrate interface became smoother and surface roughness tended to decrease as amount of YAT in electrolytic solution increased.

The coating thickness decreases with addition of YAT while it does not change significantly with the increase of its amount.

\section{References}

[1] S. Cengiz, Y. Gencer, Surf. Coat. Tech. 242, 132 (2014).

[2] Y. Cheng, E. Matykina, R. Arrabal, P. Skeldon, G.E. Thompson, Surf. Coat. Tech. 206, 3230 (2012).

[3] Y.L. Cheng, E. Matykina, P. Skeldon, G. Thompson, Electrochim. Acta 56, 8467 (2011).

[4] Y.L. Cheng, F. Wu, Nonferr. Metal Soc. 22, 1638 (2012).

[5] J. Chevalier, Biomaterials 27, 535 (2006).
[6] G. Shanmugavelayutham, S. Yano, A. Kobayashi, Vacuum 80, 1336 (2006).

[7] U. Leushake, T. Krell, U. Schulz, M. Peters, W.A. Kaysser, B.H. Rabin, Surf. Coat. Tech. 94, 131 (1997).

[8] J. Li, X.D. Bai, D.L. Zhang, H.Y. Li, Appl. Surf. Sci. 252, 7436 (2006).

[9] O. Van der Biest, E. Joos, J. Vleugels, B. Baufeld, J. Mater. Sci. 41, 8086 (2006).

[10] T. Pauporte, J. Finne, A. Kahn-Harari, D. Lincot, Surf. Coat. Tech. 199, 213 (2005).

[11] Y. Gencer, M. Tarakci, S. Cengiz, K.O. Gunduz, Adv. Mater. Res.-Switz. 445, 637 (2012).

[12] S. Cengiz, M. Tarakci, Y. Gencer, A.O. Devecili, Y. Azakli, Acta Phys. Pol. A 123, 445 (2013).

[13] Y. Gencer, M. Tarakci, S. Cengiz, J. Fac. Eng. Archit. Gaz. 26, 851 (2011).

[14] A.L. Yerokhin, X. Nie, A. Leyland, A. Matthews, S.J. Dowey, Surf. Coat. Tech. 122, 73 (1999).

[15] M. Tarakci, Mater. Charact. 62, 1214 (2011).

[16] E. Matykina, R. Arrabal, P. Skeldon, G.E. Thompson, P. Wang, P. Wood, Surf. Coat. Tech. 204, 2142 (2010).

[17] A.G. Evans, R.M. Cannon, Acta Metall. Mater. 34, 761 (1986).

[18] Y.L. Cheng, J.H. Cao, Z.M. Peng, Q. Wang, E. Matykina, P. Skeldon, G.E. Thompson, Electrochim. Acta 116, 453 (2014). 